\title{
Balancing Complex Social and Technical Aspects of Design: Exposing Engineering Students to Homelessness Issues
}

\author{
Diana A. Chen *D, Mark A. Chapman and Joel Alejandro Mejia $\mathbb{D}$ \\ Integrated Engineering, Shiley-Marcos School of Engineering, University of San Diego, San Diego, \\ CA 92110, USA; markchapman@sandiego.edu (M.A.C.); jmejia@sandiego.edu (J.A.M.) \\ * Correspondence: dianachen@sandiego.edu
}

Received: 12 June 2020; Accepted: 21 July 2020; Published: 23 July 2020

\begin{abstract}
This paper describes the development and implementation of a classroom experience involving problem-based and project-based learning with community engagement in an engineering design context. While most User-Centered Design courses ask students to critically analyze and synthesize user needs, particularly of users who they see as "not like them", our version is unique in having students wrestle with concepts of power, privilege, and oppression alongside developing prototypes that address sociotechnical aspects of engineering design that are rarely discussed in engineering courses. The course project described in this paper was developed to integrate issues of homelessness with engineering design. To achieve this goal, we partnered with a local non-profit organization that provides access to safe, mobile showers for our unhoused neighbors. Considering the context and needs of people who experience homelessness, students built solar water heater prototypes that integrated with the mobile shower units of our partners. Our goal with this course is to demonstrate to students that technical solutions are often insufficient for solving sociotechnical problems. In this case, the partnership with the non-profit organization was critical to conveying to students that engineering alone cannot solve homelessness.
\end{abstract}

Keywords: sociotechnical engineering; engineering design; social justice; homelessness; course development; project-based learning; problem-based learning; community engagement; engineering education

\section{Introduction}

Several criteria are recommended for project-based learning (PBL) to be successful [1], including basing the project on a meaningful problem and operationalizing the project with an open-ended, engaging question. In addition, sustained inquiry, where students find and use resources of their own over time; authenticity of a real-world context, process, and impact that connects to students' own concerns, interests, and identities; and student voice and choice in how they use their time and the products they create are key elements to creating an engaging project. Engineering design projects, particularly those that take user contexts into account, lend themselves especially well to PBL when students are asked to consider sociotechnical aspects that influence their technical design solutions.

While we have used PBL in the past in this course, we found that it was not a sufficient approach to engage our students with the social justice context of our curriculum, nor were we able to deeply convince students of the importance of user needs in engineering designs. As a part of our User-Centered Design course goals, we aim to help students understand that engineering alone cannot solve complex socio-political problems. For the course's final project, students design a solar water heater to help various users in situations where electric power is not available. Ideally, students must understand the user's context in order to build a prototype appropriate for the climate, budget, 
available materials, and time of use, among other variables. (For instance, a solar water heater that is only able to provide hot water when the sun is highest is not very useful to a coal miner who might only be home to take showers in the middle of the night.) Throughout several previous variations of the course and course project, students' designs and reports indicated that they seemed to only take user needs into consideration in the initial design stages and tended to ignore this context once the technical project parameters were established. However, a primary goal in this course is to have students develop a prototype that cannot be divorced from its context. Upon reflecting on these observations, we theorized that students would be more invested in the context (relative to the technical parameters) if they had a personal connection to the problem they were working to address.

As such, this paper describes a project that attempts to incorporate local justice issues with technical design by integrating elements of PBL into a new project context focused on homelessness in San Diego. We detail our attempt at navigating best practices for engaging with communities through a justice (rather than charity) approach in our project redesign, in order to elevate our PBL framework to the next level. Our new approach sought to answer the question: "In what ways does the integration of social issues, such as homelessness, influence engineering students' perceptions of the viability of technical solutions?"

\subsection{Institutional Context}

The origin of this unique User-Centered Design course stems from the institutional context of our university. The University of San Diego (USD) is a primarily undergraduate, liberal arts, contemporary Catholic institution that embraces the Catholic moral and social tradition in its mission and values. USD is also designated as an Ashoka U "Changemaker Campus", a recognition of our university's commitment to finding sustainable solutions to the world's most pressing problems. Furthermore, our university's Envision 2024 strategic plan, "Because the World Needs Changemakers", aligns university-wide curricula with the values of our institution. In keeping with our mission, all USD graduates complete two courses with the diversity, inclusion, and social justice (DISJ) Core flag, which seeks to help students develop critical self-reflection and the ability to analyze the complexities of social constructions in everyday life.

As a result of our campus environment, our version of User-Centered Design has evolved to be unique in its objective to cover topics including justice, power, intersectionality, and privilege and oppression, but has been in flux as social and political contexts and activities have slowly been tested within the course [2]. In addition, USD's Changemaker Hub-which is described as both a place and a process that highlights the interconnections of people, activities, and organizations that constitute changemaking-launched an Urgent Challenges Collective initiative in 2019 to study and address homelessness and food insecurity in our local community. In response to this initiative, we redesigned the course's final project to focus on issues surrounding homelessness. As such, this paper describes the latest developments of a sociotechnical, solar water heater project in our course that integrates issues of homelessness with engineering design.

\subsection{Homelessness: Context and Misconceptions}

San Diego County has the fourth highest homeless population in the United States, half of which are unsheltered [3]. Given this large local population, centering a project around homelessness in San Diego is a powerful way to help students recognize and attempt to address important issues in their own backyards. The context of homelessness is also an opportunity for us, as instructors, to breakdown misconceptions about individuals facing homelessness as a way to humanize this often-neglected population. These misconceptions range from the causes of homelessness to the characteristics of individuals experiencing homelessness. One prevailing misconception is that all individuals experiencing homelessness live on the streets, when, in fact, many live in their cars, and some may even drive these cars to their full-time jobs. Additionally, many think that a large majority of people experiencing homelessness have issues with substance abuse; however, this is true 
for only 3\% of homeless individuals in San Diego. Another misconception is that many homeless individuals have a severe mental illness, while this only true for $4 \%$ of the homeless population in San Diego. Lastly, some people may be frightened by and believe individuals experiencing homelessness are criminals, but homeless individuals are much more likely to be victims of crime than commit crimes [4]. By integrating issues of homelessness into our engineering course, we hoped to demystify these issues and dispel misconceptions for our students.

\section{Theoretical Framework: Problem-Based and Project-Based Learning with Communities}

Engineers often use personal and shared beliefs and values when solving ill-structured problems-problems that do not have a single or correct answer [5]. The type of engineering project we assigned to our students was ill-structured in nature because it included multiple perspectives, interpretations, and holistic approaches. These problems are not constrained by the content domains being studied in classrooms; they are dynamic, involve multiple solutions, and the constraints can be both engineering and non-engineering related [6]. Ill-structured problems may affect any aspect of everyday life, and finding a solution to such a problem involves the use of different processes similar to those used in the professional practice of engineering [6].

Finding solutions to problem-based activities, as well as more technical problems, involves the integration of science, mathematics, and technology, but also everyday life knowledge and prior experiences [6]. Providing solutions to ill-structured problems requires the individual to "make judgments and express personal opinions or beliefs about the problems" [6] (p. 103). In engineering education, we have seen an increasing use of engineering design activities that are problem-based and ill-structured [6-9] as a strategy to engage students and enhance systems thinking, dispositions, and habits of mind. The dynamic nature of problem-based learning allows for the integration of several domains (i.e., problem scoping, idea generation, evaluation, and solution quality) and provides an opportunity to engage in interdisciplinary activities where the constraints may or not be engineering-related $[6,7,9-11]$. They also provide a venue for the students to connect with their everyday life, and allow the students to take personal ownership of the context of solving the problem $[6,10,11]$.

Many engineering programs that include PBL in their curriculum base their projects on community engagement activities or are developed through community partnerships [12-14]. We have seen a significant increase in the number of community engagement programs in the last two decades [15], including recently on our own campus with the institutional push for engaged scholarship, the practice of changemaking, and to become an anchor institution in our local community. In addition, there are a growing number of classes and programs in engineering that attract students to "help communities in need" [16]. This may be due in part to the history of engineering's involvement in sustainable development, where engineers have viewed people as clients, rather than users or citizens. Lucena [17] emphasizes how the way in which engineers view the people they try to serve can shape the way we listen and work with them. Instead, engineering students should be reflective of their own motivations as they engage with "engineering to help", where we often see recipients of our help (the ones with problems) as lesser-than or inferior to us (the problem-solvers) [12].

As such, partnerships between institutions of higher education and community organizations should be carefully approached from a justice rather than charity perspective [18]. Thompson et al. [19] discuss that transactional interactions between programs and communities can create an "us vs. them" mentality and lead to negative interactions where the programs make decisions for the community without input or dialog. Rather, the "best practices in engagement between an academic institution and the community are characterized by mutually beneficial relationships, clear inclusion of the community partner's voice, intentional reflection by the students on their experiences, and a longer length of commitment" [20] (p. 1).

While the terms project-based learning and problem-based learning are often used interchangeably, they are not entirely the same concept [21]. Both try to achieve better student learning outcomes, but problem-based learning utilizes student discovery as opposed to project-based learning, which 
provides students with guided processes. In our case, the design project that students work on integrates guided processes focused around a project prompt (lending itself more to the project-based learning concept), but our focus on issues of homelessness presents an ill-structured problem to students (forming the context of the project around problem-based learning), especially for within an engineering context.

\section{Methodology: Building the Project}

\subsection{Building a Partnership with Think Dignity}

As we redesigned the course project to better reflect the sociotechnical nature of engineering alongside integrating elements of PBL, we reframed our goals around training our students. Specifically, we focused on encouraging our students to understand problems not as right or wrong, but to recognize, learn from, and value perspectives other than their own [22]. We decided to partner with a local organization, Think Dignity, to provide a relatable context for students to engage with. Think Dignity is a non-profit organization that provides hands-on activism, legal advocacy, and resources to people experiencing homelessness. In particular, Think Dignity offers a Fresh Start Showers program that provides safe, mobile shower facilities through San Diego County. The shower modules are set up at partner sites throughout the county that provide electricity and water to the mobile showers, in addition to space for additional charities to provide supplies and services.

After an initial call with the executive director to confirm the appropriateness and practical use of a solar water heater, we attended a community-facing meeting hosted by Think Dignity to learn more. At this meeting, we learned about on-going efforts by Think Dignity and also heard directly from several individuals experiencing homelessness. We found that this initial meeting helped us, as instructors, reflect on our own privileges and lifestyles. Later, this personal reflection proved to be useful in demonstrating empathy for our users in a way that students could learn from.

We continued to build our partnership with Think Dignity by volunteering at one of the mobile shower events. In person, we met individuals experiencing homelessness in search of a hot shower, interacted with compassionate program coordinators and volunteers, and learned about the specifics of the mobile shower unit for integration with our course project. We helped, starting with the setup of the operation and ending with the discharge of graywater as the event closed out for the day. The small details we learned by attending this event, such as how water was connected to the unit and where water was sourced, all played a role in designing an authentic project experience [1] for our students.

\subsection{Building a Context around Homelessness}

To prepare our students to engage with the social factors influencing their project designs, they were assigned to participate in Homelessness and Food Insecurity Awareness Week, which consisted of a series of on-campus events. Students completed a four-part assignment exploring homelessness. First, each student was required to visit the mobile shower unit on campus that Think Dignity had on display. Students were informed that their final project would interface with this unit and were encouraged to take pictures and ask questions. Second, students were assigned to visit interactive exhibits on display, which included testimonials from individuals (and particularly members of the USD community) who have experienced homelessness. These exhibits, as shown in Figures 1-3, for example, used multi-modal texts, such as statistical data, diagrams, photos, artwork, personal testimonies, and documentaries, among others, to convey information. A multimodal approach seeks to not only explore written and spoken language, but also engage students through a range of modes while increasing students' interests through different resources [23]. It was surprising for many to discover that there were 150 current students experiencing homelessness ( $2 \%$ of our generally wealthy student population) [24]. Third, students could choose to attend one event of their choice from a provided list, which included a Housing and Food Access Resource Fair, a documentary and discussion, 
a candlelight vigil where stories about people experiencing homelessness were shared, or attending a political festival centered around homelessness.

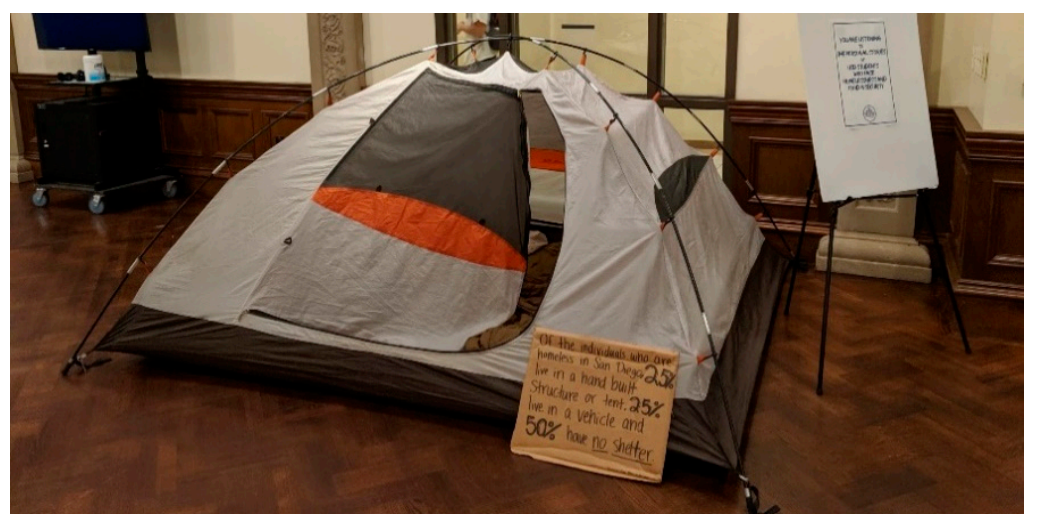

Figure 1. Tent exhibit from Homelessness Awareness Week, with a personal testimony voiceover from a student.

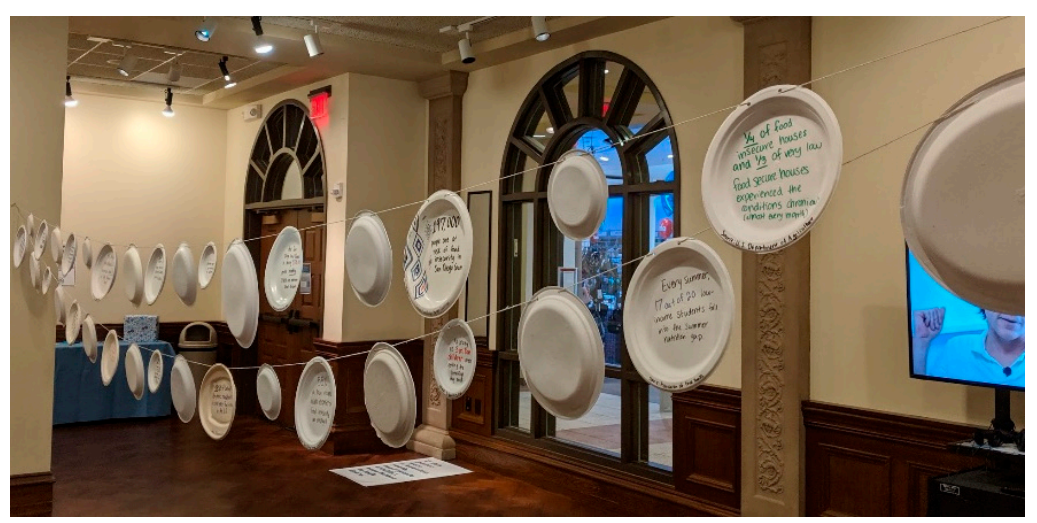

Figure 2. Exhibit with statistics about food insecurity from Homelessness Awareness Week.

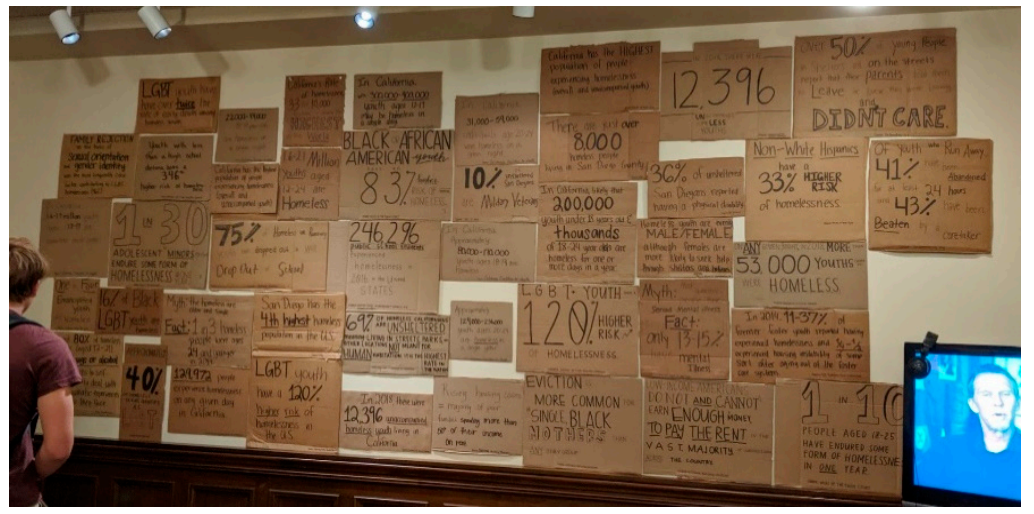

Figure 3. Exhibit on different types of discrimination that can lead to homelessness from Homelessness Awareness Week.

In addition, students were assigned to create an annotated bibliography to build knowledge on both the social and technical aspects of the project. The annotated bibliography assignment included required readings on stereotypes and criminalization of homelessness [25], perceptions, and discrimination of the homeless [26-28], information on the mobile shower program provided by Think Dignity [3], and general information and local statistics about the homeless population in San Diego $[29,30]$. In our debriefing sessions during class time, we often discussed issues of homelessness at the university, reflected on information learned from the class activities and assignments, and examined the myths 
around homelessness that arose as we dove into this topic throughout the project. The conjunction of the Awareness Week assignments and the self-guided research contributed to the project-based learning base we used for the course. By exploring these resources, students engaged with an open-ended question, an authentic real-world context, and were able to invoke their voice and choice [1] in the types of resources they pursued.

Finally, to provide additional information to our students, we invited the program operations manager from Think Dignity to give a presentation about the organization and the issues they tackle, including the misconceptions identified in Section 1.2, above. This representative also provided specific details about the mobile shower units that would be useful to students in actualizing their physical prototypes. The students were instructed to design a solar water heater in a way that related the design back to the user by addressing the social, economic, historical, and cultural factors that contribute to homelessness, and communicate the impact of their solar water heater design as a critical component to positively contribute to Think Dignity's mission. The main deliverables for this project were a functioning prototype and a final report detailing the context of their designs as well as outlining the design process and prototype development, testing, and assessment.

\subsection{Data Collection and Analysis}

We launched this new project approach in Fall 2019, with three sections of students primarily in their second year of college. Students across three different sections of the User-Centered Design course were given a survey where demographic information was collected. Survey results indicate that, from the 62 students surveyed, 42 self-identified as males and 20 self-identified as females. Students also provided data for their age ranges, with one selecting 31-35, one aged 36 or older, and the rest between $18-25$ years old.

The students were asked to write a reflection on their experiences at these events. To help the students reflect, our assignment prompts included questions such as, "What did you learn?", "Was anything surprising to you?", "How do the experiences of individuals that experience homelessness that you learned about during Awareness Week compare/contrast with your own life experiences?" and "How or in what ways did Awareness Week help demystify some of your own preconceptions about homelessness?" The responses to these questions were collected and used as the primary source for analysis. In addition, we collected the artifacts created by the students and their final project reports to get a better sense of how the students conceptualized homelessness, how they integrated information obtained from their annotated bibliographies to their final project, and to determine how their perceptions of homelessness influenced their approach to the sociotechnical problem presented to them.

At the end of the data collection, all authors analyzed the data following a deductive coding approach to qualitative research [31]. An open coding approach was used to identify shared meaningful themes found in the responses provided by the students. First, responses to questions and reports were read carefully and emergent themes were discussed among all authors. We applied dual criteria [32] to identify internal homogeneity and external heterogeneity. The results and analyses of the data are presented in the following sections. It is important to note that these are representative examples of what was observed throughout the data collected to provide a descriptive interpretation of the data [33].

\section{Results}

\subsection{Responses to Homelessness Awareness Week}

The partnership created with Think Dignity, along with those activities implemented throughout the project, allowed students to better understand the context of a complex sociotechnical issue. An examination of students' written reflections on participating in Homelessness Awareness Week revealed a change in their perspectives on homelessness. Specifically, many students expressed surprise 
at learning their beliefs related to the causes of homelessness and the demographics of people that experience homelessness were myths. Many students were surprised that there are people their own age that experience homelessness in their community. For example, one student indicated the following in his response:

"...The ones [statistics] that hit hardest to home were the facts about people my age. I had no clue that $41 \%$ of college students experienced low food security or that 1 in 3 people experiencing homelessness were under age 24. This surprised me because I never considered that any of my friends could be homeless or unsure of when their next meal would come."

After participating in Homelessness Awareness Week, the students had the opportunity to learn about the demographics of those who experience homelessness. Several students indicated that one of the most interesting points made by the exhibit was that individuals of all ages can experience homelessness. In addition, other students focused on the locality of the problem and how that made it more tangible for students. One of the students indicated:

“...I already knew how horrific the number of homeless people in San Diego is, but I never would have guessed that there were students at this school, which has one of the most expensive costs of attendance of the colleges in California. The testimonials were from students who study at USD, then go "home" to their car to sleep, or don't even have a car for shelter. I think this part of the exhibit surprised me so much because it was easier to envision myself in their position."

Learning about the San Diego statistics, and the fact that students at their institution experience homelessness, made the issue more relevant. During the debriefing conversations with students, they indicated that it was surprising to know, and could not grapple with the fact that a wealthy school with majority White, middle to upper class students, had to confront the realities of homelessness among its student population. Making the problem more tangible and not separate from their lived realities contributed to students engaging in more critical conversations about the sociotechnical nature of the problems, and the fact that engineers cannot solve problems alone.

Many students also reflected on the statistics centered on the causes of homelessness. For example, several students highlighted that race and gender pay a role in the likelihood of homelessness. One student responded with the following statement:

"...There were a number of other statistics as well that talked about the increased likelihood of minority groups to be homeless. This surprises me because it again shows how social factors are linked with homelessness. In general, the more one is alienated from society (from being a minority in any way) it seems as though one is more likely to be homeless."

This excerpt indicates that the student became more aware of the impact that social constructions play in increasing the likelihood of homelessness. Another student indicated that preconceived notions of what homelessness is or the factors that influence the likelihood to experience homelessness, such as addiction, are sometimes mere misconceptions. He said:

“...I imagined most homeless people lived in the streets and probably had addiction issues. However, I was shocked to discover the amount of homeless people that live in a car or have their own outdoors equipment... I learned that many homeless people may be homeless through no fault of their own. ...These unfortunate circumstances revealed to me that a considerable amount of people are one life event away from being homeless themselves."

This excerpt demonstrated that the activities enabled students not only to learn more about homelessness, but also to challenge their own preconceived notions and stereotypes about homelessness. Students had previously discussed in class how social constructions and intersectionality need to be 
considered in user-centered designs. This experience allowed students to gain a better understanding of how social constructions are linked to homelessness and influence decision-making processes aimed at determining who gains and who loses. It is also important to note that, despite the fact that the exhibit had not only statistics about homelessness but also testimonials from individuals that experience homelessness, most of the students' reflections focused on the statistics and, in very rare instances, on the testimonials of individuals.

\subsection{Solar Water Heater Prototypes and Design Reports}

The students developed prototypes of solar water heaters that integrated with Think Dignity's mobile shower unit. Figure 4 depicts four examples of the water heaters that students created. While the integration of some designs with Think Dignity's mobile shower unit were unclear at first glance, students were asked to explain these connections in their design reports. Students' design ideas included, among others, a solar reflector array, a copper coil, insulated pipes, and a hybrid-heat exchanger using a car's exhaust system.
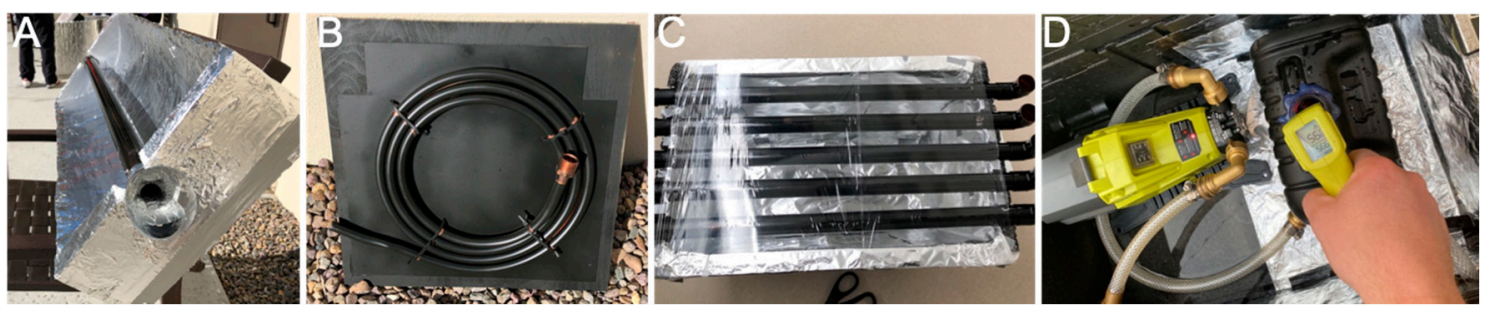

Figure 4. Representative water heater prototypes. Panels $(A-C)$ depict designs of solar water heaters, while panel (D) shows a design that heats water using heat output from a car's exhaust system.

The final design reports detailed the context of students' designs, the design process, testing methods, and data generated from testing their prototypes. While the resulting prototypes created might be usable in any context, students had to convincingly describe how their consideration of users who were experiencing homelessness was a factor in the context of their designs. Upon examining the report introductions, we observed that students were able to accurately describe the causes of homelessness in their reports, rather than perpetuating stereotypes and myths. The following excerpts describe how two teams of students presented homelessness:

"While the stereotype is that most homeless people are unemployed, have a mental illness, and/or have substance abuse problems, studies have shown that a fair portion of the homeless population are employed and less than half have a mental illness or substance abuse problem."

"Having a minimum-wage job, being a veteran, part of the LGBTQ community, having substance abuse issues, having a disability, or being a single parent, all increase the chances of being or becoming homeless."

While these descriptions of homelessness introduce aspects that are not traditionally associated to experiencing homelessness, students did not indicate how they themselves changed their own perceptions about homelessness. In addition to identifying the typical causes of homelessness in general, students also identified issues that are specific to the San Diego area. The following excerpts illustrate how students connected issues of homelessness to the local context:

"There are many economic and cultural factors that contribute to the issue of homelessness. San Diego has extremely high costs of living and most salaries are not enough to cover basic needs, much less live comfortably."

"Economic considerations are probably the key factor that drives the issue of homelessness in San Diego. The State of California in general and the City of San Diego in particular have experienced skyrocketing housing costs and costs of living." 
The goal of the project was to help students connect a problem to a social context, and the different activities assigned for the project contributed to students (re)contextualizing the problem. These excerpts also shed light on the importance of developing activities that contribute to students understanding problems as sociotechnical. In this case, students were able to situate issues of homelessness in a local setting and recognized that engineering problems are not separate from social issues.

\section{Discussion}

As indicated by the students' responses, this community partner-driven, problem-based learning experience allowed them to explore not only the technical aspects of the project, but also challenge their own perceptions about homelessness by analyzing the sociotechnical aspects of the problem. The issue of homelessness was central to the learning experience, thus becoming the driving force for guided inquiry [6] and knowledge construction [34]. The students' research about homelessness was used as a way to help them direct their own learning to build knowledge that could inform their course of action. As indicated by Thomas [34], project-based learning, similar to the one described in this paper, should incorporate activities that allow for new knowledge construction as a way to incentivize students to participate in discovery-driven activities.

Students' reflections from their Homelessness Awareness Week assignment, as well as passages from their reports (as shown above), demonstrate the impact of project-based learning that incorporates real-life, authentic problems that have no singular answer. As students learned more about the problem, they realized that the issue of homelessness may not necessarily be solved through a solar water heater. Their inquiry process expanded beyond the boundaries of the project's problem initial framing. For instance, some students started to analyze the historical, social and political aspects of how engineering work may not address the true problems affecting marginalized communities. One of the teams suggested that a solar water heater would not address the "real" issues related to homelessness, and consequently pushed to broaden the project scope with their prototype, as shown in Figure 4D, when they realized the impact of the original project prompt (which prescribed solar energy as the heat source) would be minimal. Freire [35] describes this process as the "transitivity of consciousness" of students where they begin to reflect on how they are situated in the world around them, their roles and responsibilities, and the dialogue that is necessary to engage in meaningful ways with their surroundings. While this manifested as "students breaking rules" in practice, this sort of boundary-pushing reflects a level of success in students learning to identify true user needs above and beyond the problems posed by the professor for learning's sake. We believe that reframing this PBL course experience through partnership with a real community stakeholder helped students to more deeply grasp the nuances of user-centered design and the role the "social" plays in engineering work. Our project approach challenged students to grapple with the idea that engineering alone cannot "solve" homelessness, as there are factors external to the technical parameters of a project that can impact homelessness, such as high costs of living and discrimination against certain types of individuals.

While our scaffolding of social issues through class activities and assignments helped to demystify homelessness and broadened our students' understanding of sociotechnical issues, in the end they continued to be solution-driven in their project prototypes. As instructors, we learned that deeply impacting students' mindsets about the sociotechnical nature of engineering is difficult to achieve in a single semester and will likely require follow-on courses that continue to drive this point home. Fortunately, this User-Centered Design course is the first of many in our program where engineering students grapple with these realities [2,36-42]. Despite this, we saw that our students began developing a critical consciousness, even if it was not explicitly tied to the engineering design (and so did not lead to our specific desired outcome for this project). Unfortunately, this study did not involve interviews or focus groups that could lead to data containing thick descriptions of students' ways of thinking. Further work will be needed to develop the course in such a way that social issues are tied directly to engineering design. One limitation of the project was our prescription of a solar water heater design 
rather than pushing students to identify on their own what needs already existed in the homeless community. We acknowledge that the project still needs to be more problem-driven and that we need to guide students towards the problem that needs addressing rather than guiding them towards iterations of what a single solution might look like. In future iterations we plan to have students identify user needs in the homeless community and design an artifact centered on their identified need.

Although there were many positive aspects to the project, there were also some issues that could be improved for future iterations. For example, students were exposed to a series of activities and presentations that are not part of the curriculum or available year-round. We partnered with several individuals on campus and off-campus, but we recognize the challenges that come with organizing and, most importantly, maintaining those relationships. As more engineering programs seek to engage in project-based learning that provides a holistic and sociotechnical view of engineering, particularly through engaging with communities, it is important to strategize how such activities will be stratified and organized so that students can engage in meaningful conversations that can help dismantle the complexities of engineering activity. Lastly, as instructors, we realized the importance of working with a community partner and the significance of personal reflection in developing projects that can potentially (re)define how engineers approach problem solving.

In the end, students were able to challenge their own perceptions of homelessness and engaged in challenging conversations in the classroom. Making the project tangible and observable (e.g., making homelessness visible and pertinent to the San Diego context) contributed to students acknowledging that engineers solve sociotechnical problems. Moreover, this experience provided students with the context to realize that not all problems can be solved by engineers alone. In conversations with the students during classroom discussions, it was clear that students struggled coming to terms with the fact that a problem-based learning experiences may contain many nuances when social issues are central to the project. Although the experience contributed to students challenging their own pre-conceived notions about homelessness, they still struggled with making the social context the fundamental piece to establish a viable technical solution.

Overall, by creating this course project centered around homelessness, students were pushed to reflect on their own preconceptions and motivations, to educate themselves on historical, political, and social contexts, and to understand the user's point of view before jumping into action to "solve their problems". As demonstrated in their project deliverables, this project redesign was successful in helping students learn to approach users as people rather than clients and better appreciate the roles that empathy and understanding (compared to problem-solving) play in engineering work. However, more work is needed to structure a project where the final design prototype is more deeply integrated into its social context. In future iterations, we plan to keep the context of homelessness, but instead allow students to identify an existing user need and create a solution to address that need. In this way, we will give the students more autonomy to address this identified user need instead of assigning all students to create a solar water heater.

Author Contributions: Conceptualization, D.A.C., M.A.C., and J.A.M.; methodology, D.A.C., M.A.C., and J.A.M.; formal analysis, J.A.M.; resources, D.A.C. and J.A.M.; data curation, M.A.C.; writing-original draft preparation, D.A.C., M.A.C., and J.A.M.; writing-review and editing, D.A.C., M.A.C., and J.A.M.; funding acquisition, M.A.C. and J.A.M. All authors have read and agreed to the published version of the manuscript.

Funding: This research was funded by the Course Development Program through the Urgent Challenges Collective at the University of San Diego.

Acknowledgments: We would like to thank Merlynn Watanabe and Mitchelle Woodson from Think Dignity for their time and contributions to developing an authentic learning experience for our students. We would also like to thank the Urgent Challenges Collective and the USD Strategic Initiative for their support of our work.

Conflicts of Interest: The authors declare no conflict of interest. 


\section{References}

1. Essential Project Design Elements Checklist. 2015. Available online: https://cpb-us-w2.wpmucdn.com/wp. wpi.edu/dist/e/220/files/2017/06/Essential-Project-Design-Elements-Checklist.pdf (accessed on 2 July 2020).

2. Mejia, J.A.; Chen, D.A.; Dalrymple, O.O.; Lord, S.M. Revealing the Invisible: Conversations about -Isms and Power Relations in Engineering Courses. In Proceedings of the ASEE Annual Conference Proceedings, Salt Lake City, UT, USA, 23-27 June 2018.

3. Think Dignity. Fresh Start Showers; Internal Report; Think Dignity Hands-on Advocacy \& Activism with the Homeless: San Diego, CA, USA, 2016.

4. Watanabe, M. Don't Look Away: Addressing Homelessness in San Diego County; University of San Diego: San Diego, CA, USA, 2019.

5. Jonassen, D.H.; Cho, Y.H. Fostering argumentation while solving engineering ethics problems. J. Eng. Educ. 2011, 100, 680-702. [CrossRef]

6. Jonassen, D.H. Engineers as problem solvers. In Handbook of Engineering Education Research; Johri, A., Olds, B.M., Eds.; Cambridge University Press: New York, NY, USA, 2014; pp. 103-118.

7. Atman, C.J.; Adams, R.S.; Cardella, M.E.; Turns, J.; Mosborg, S.; Saleem, J. Engineering design processes: A comparison of students and expert practitioners. J. Eng. Educ. 2007, 96, 359-379. [CrossRef]

8. Dym, C.L.; Agogino, A.M.; Eris, O.; Frey, D.D.; Leifer, L.J. Engineering design thinking, teaching, and learning. J. Eng. Educ. 2005, 94, 103-120. [CrossRef]

9. Jonassen, D.; Strobel, J.; Lee, C.B. Everyday problem solving in engineering: Lessons for engineering educators. J. Eng. Educ. 2006, 95, 139-151. [CrossRef]

10. Lehmann, M.; Christensen, P.; Du, X.; Thrane, M. Problem-oriented and project-based learning (POPBL) as an innovative learning strategy for sustainable development in engineering education. Eur. J. Eng. Educ. 2008, 33, 283-295. [CrossRef]

11. Zhou, C.; Kolmos, A.; Nielsen, J.F.D. A problem and project-based learning (PBL) approach to motivate group creativity in engineering education. Int. J. Eng. Educ. 2012, 28, 3-16.

12. Lucena, J.; Schneider, J.; Leydens, J.A. Engineering and Sustainable Community Development. Synth. Lect. Eng. Technol. Soc. 2010, 5, 1-230. [CrossRef]

13. Schneider, J.; Leydens, J.A.; Lucena, J. Where is "community"?: Engineering education and sustainable community development. Eur. J. Eng. Educ. 2008, 33, 307-319. [CrossRef]

14. Bielefeldt, A.R.; Paterson, K.G.; Swan, C.W. Measuring the Value Added from Service Learning in Project-Based Engineering Education. Int. J. Eng. Educ. 2010, 26, 535-546.

15. Lucena, J.; Schneider, J. Engineers, development, and engineering education: From national to sustainable community development. Eur. J. Eng. Educ. 2008, 33, 247-257. [CrossRef]

16. Schneider, J.; Lucena, J.; Leydens, J.A. Engineering to help. IEEE Technol. Soc. Mag. 2009, 28, 42-48. [CrossRef]

17. Lucena, J.C. Engineers and Community: How Sustainable Engineering Depends on Engineers' Views of People. In Handbook of Sustainable Engineering; Joanne, K., Lee, K.M., Eds.; Springer: Dordrecht, The Netherlands, 2013.

18. Marullo, S.; Edwards, R. From Charity to Justice: The Potential of University-Community Collaboration for Social Change. Am. Behav. Sci. 2000, 43, 895-912. [CrossRef]

19. Thompson, J.D.; Lucena, J.C.; Lima, M.; Jesiek, B.K. Special Session: Building Intentional Community Partnerships; ASEE Annual Conference \& Exposition: Seattle, WA, USA, 2015.

20. Lima, M.; Christy, A.D. Service Learning in Biological and Agricultural Engineering: Journeys in Community Engagement; ASEE Annual Conference \& Exposition: Columbus, OH, USA, 2017.

21. Kolmos, A.; De Graaff, E. Problem-based and project-based learning in engineering education: Merging models. In Cambridge Handbook of Engineering Education Research; Cambridge University Press: Cambridge, UK, 2015; pp. 141-160. ISBN 9781139013451.

22. Lucena, J.; Downey, G.L. Engineering Cultures: Engineering Problem Solving Through Humanistic And Global Perspectives; ASEE Annual Conference \& Exposition: Charlotte, NC, USA, 1999.

23. Archer, A. A multimodal approach to academic "literacies": Problematising the visual/verbal divide. Lang. Educ. 2006, 20, 449-462. [CrossRef]

24. Economic Diversity and Student Outcomes at University of San Diego. Available online: https://www. nytimes.com/interactive/projects/college-mobility/university-of-san-diego (accessed on 11 June 2020). 
25. Truong, S.V. "Please Do Not Feed the Homeless": The Role of Stereotyping and Media Framing on the Criminalization of Homelessness. Ph.D. Thesis, University of California Santa Cruz, Santa Cruz, CA, USA, 2012.

26. Le Dantec, C.A.; Edwards, W.K. Designs on Dignity: Perceptions of Technology Among the Homeless. In Proceedings of the CHI 2008 Proceedings: Dignity in Design, Florence, Italy, 5-10 April 2008; pp. 5-10.

27. Lurie, K.; Schuster, B.; Rankin, S. Discrimination at the Margins: The Intersectionality of Homelessness \& Other Marginalized Groups. Homeless Rights Advocacy Proj. 2015, 8.

28. Finley, S. The faces of dignity: Rethinking the politics of homelessness and poverty in America. Int. J. Qual. Stud. Educ. 2003, 16, 509-531. [CrossRef]

29. WeALLCount Annual Report: San Diego County; Regional Task Force on the Homeless: San Diego, CA, USA, 2018.

30. WeALLCount Data: General Results; Regional Task Force on the Homeless. 2019. Available online: https:// www.rtfhsd.org/wp-content/uploads/2019/04/Pages-from-2019-General-Fact-Sheet-0429199_final.pdf (accessed on 11 November 2019).

31. Saldaña, J. The Coding Manual for Qualitative Researchers, 2nd ed.; SAGE Publications: Thousand Oaks, CA, USA, 2015; ISBN 9781473902497.

32. Patton, M.Q. Qualitative Evaluation and Research Methods, 2nd ed.; SAGE Publications: Newbury Park, CA, USA, 1990.

33. Mitchell, J.C. Case and situation analysis. Sociol. Rev. 1983, 31, 187-211. [CrossRef]

34. Thomas, J.W. A Review of Research on Project-Based Learning; The Autodesk Foundation: San Rafael, Philippines, 2000.

35. Freire, P. Education for Critical Consciousness; Seabury Press: New York, NY, USA, 1973.

36. Chen, D.A.; Hoople, G.D. Contextualizing a New General Engineering Curriculum in the Liberal Arts. In Proceedings of the ASEE Annual Conference Proceedings, Columbus, OH, USA, 24-28 June 2017.

37. Lord, S.M.; Mejia, J.A.; Hoople, G.D.; Chen, D.A. Special Session: Starting a Dialogue on Decolonization in Engineering Education. In Proceedings of the 2019 Frontiers in Education Conference (FIE), Covington, KY, USA, 16-19 October 2019.

38. Chen, D.A.; Przestrzelski, B. Let the Composites Speak: Using Statics to Critically Evaluate Gerrymandering. In Proceedings of the 2019 Frontiers in Education Conference (FIE), Covington, KY, USA, 16-19 October 2019.

39. Hoople, G.D.; Mejia, J.A.; Chen, D.A.; Lord, S.M. Reimagining Energy: Deconstructing Traditional Engineering Silos Using Culturally Sustaining Pedagogies. In Proceedings of the ASEE Annual Conference Proceedings, Salt Lake City, UT, USA, 23 June-27 July 2018.

40. Hoople, G.D.; Mejia, J.A.; Chen, D.A.; Lord, S.M. Board 66: Reimagining Energy Year 1: Identifying Noncanonical Examples of Energy in Engineering. In Proceedings of the ASEE Annual Conference Proceedings, ASEE Annual Conference Proceedings, Tampa, FL, USA, 16-19 June 2019.

41. Chen, D.A.; Wodin-Schwartz, S. Contextualizing Statics: Our Process and Examples. In Proceedings of the 2019 ASEE Annual Conference \& Exposition, Tampa, FL, USA, 16-19 June 2019.

42. Lord, S.M.; Mejia, J.A.; Hoople, G.; Chen, D.; Dalrymple, O.; Reddy, E.; Przestrzelski, B.; Choi-Fitzpatrick, A. Creative Curricula for Changemaking Engineers. In Proceedings of the 2018 World Engineering Education Forum-Global Engineering Deans Council (WEEF-GEDC), Albuquerque, NM, USA, 12-16 November 2018; pp. 1-5.

(C) 2020 by the authors. Licensee MDPI, Basel, Switzerland. This article is an open access article distributed under the terms and conditions of the Creative Commons Attribution (CC BY) license (http://creativecommons.org/licenses/by/4.0/). 